\title{
An Innovative Multicriteria Decision-Making Tool for Building Performance Optimization
}

\author{
Abdelhadi Serbouti \\ Hassan First University of Settat \\ FST, Laboratory of Radiation - Matter \& Instrumentation \\ Settat, Morocco \\ abdelhadiserbouti@gmail.com \\ El Mostafa Oualim \\ Hassan First University of Settat \\ ISSS, Laboratory Health Sciences and Technologies \\ Settat, Morocco \\ oualim@uhp.ac.ma
}

\author{
Mourad Rattal \\ Hassan First University of Settat \\ FST, Laboratory of Radiation - Matter \& Instrumentation \\ Settat, Morocco \\ mourad.rattal@gmail.com \\ Azeddine Mouhsen \\ Hassan First University of Settat \\ FST, Laboratory of Radiation - Matter \& Instrumentation \\ Settat, Morocco \\ az.mouhsen@gmail.com
}

\begin{abstract}
Buildings are accountable for nearly $40 \%$ of global greenhouse gas emissions. Their overall efficiency is thus a major pillar to optimize energy consumption and to mitigate engendered global warming. The current work takes part in this global dynamic. Indeed, we developed a standalone decision-aid tool based on sensitivity analysis, multiobjective optimization, and artificial neural networks to design a new generation of energy-efficient buildings. The tool aims to allow benefiting from Sobol' sensitivity analysis samplings to instantaneously generate sensitivity indexes and perform multicriteria optimizations. This efficient process allows both understanding buildings' complex behavior (by ranking the impact of the inputs parameters on the outputs and highlighting their interactions) and optimizing their overall performance. The main advantages of this method are the time gaining and the provision of relevant outputs to analyze the buildings' design. The tool was successfully used to solve constrained 13-input parameters with 5-criteria on TRNSYS simulation program, considering the impact of global warming.
\end{abstract}

Keywords-energy efficiency; sensitivity analysis; multiobjective optimization; polynomial regression; global warming

\section{INTRODUCTION}

Climate change continues to have an impact on the planet and therefore requires global mobilization and commitment to encounter sustainable solutions, reducing its criticality for future generations. In those instances, the building sector is in the first category targeted to bring solutions to reduce energy consumption, while maintaining a high level of comfort to occupants. As a matter of fact, the production of building materials and their operation account for the $36 \%$ of the world's final energy consumption and nearly $40 \%$ of carbon dioxide emissions in 2017 [1]. Energy saving and the rationalization of resource use are paramount in all stages of any building's life cycle. The implementation of efficient solutions starts from the early technical design phase of any project. This decisive step requires the development of models to control the energy consumption behavior of the building and of its components. The choice of a building configuration depends on several factors, including energy performance, occupant comfort, economic or environmental constraints. The implementation of energy-efficient buildings is thus subject to several criteria. To help designers and decision makers in taking better and faster decisions, the use of decision support tools is essential. Among these tools, sensitivity analysis, metamodeling, and multiobjective optimization are very efficient in optimal building design. In state of the art energy efficiency, sensitivity analysis and multiobjective optimization are usually used independently. Authors in [3] performed sensitivity analysis on the heating and cooling energy flexibility of residential buildings. Their goal was to analyze the effects of the building envelope, users' behavior, and weather conditions on the flexibility indicators for three reference apartments. Authors in [4] performed sensitivity analysis of workspace conflicts according to changing geometric conditions. Authors in [5] proposed a multi-objective particle swarm algorithm to optimize the energy performance of buildings. Authors in [6] investigated a sustainable approach in the design of the administrative building where the design aims to deliver an energy-sufficient yet aesthetically pleasing building.

The state of the art lacks studies combining the two methods. Thus, the novelty of the current work is to propose a methodology that combines their strengths by incorporating them in a new standalone tool. The tool allows a relevant and efficient decision aid to buildings designers, and is easily interfaced to major dynamic simulation tools such as TRNSYS and EnergyPlus [7].

\section{MATERIALS AND METHODS}

Many standalone Graphical User Interfaces (GUIs) perform Multiobjective Optimization on TRNSYS. Authors in [8] did a 
comparative study of these tools by answering "Yes" or "No" to four questions (freeware, multiobjective optimization, parallel simulations, discrete and continuous input parameters). Previous studies [9, 10] used Genopt and MOBO tools to optimize the energy performance of a building in the city of Settat. These tools lack flexibility and do not offer a wide spectrum of decision-making to their users. To remedy these limitations, we developed our Sensitivity Analysis and Multiobjective Tool (SAMOT) on Python. The libraries SALib [11], Platypus [12] and Scikit-learn [13] were adapted and used. The source code will be available for Python skilled users along with a GUI for less trained users. We summarize the decision-making methods, incorporated in SAMOT tool, in the following diagram. We used the genetic algorithm NSGA-II for the multiobjective optimization.

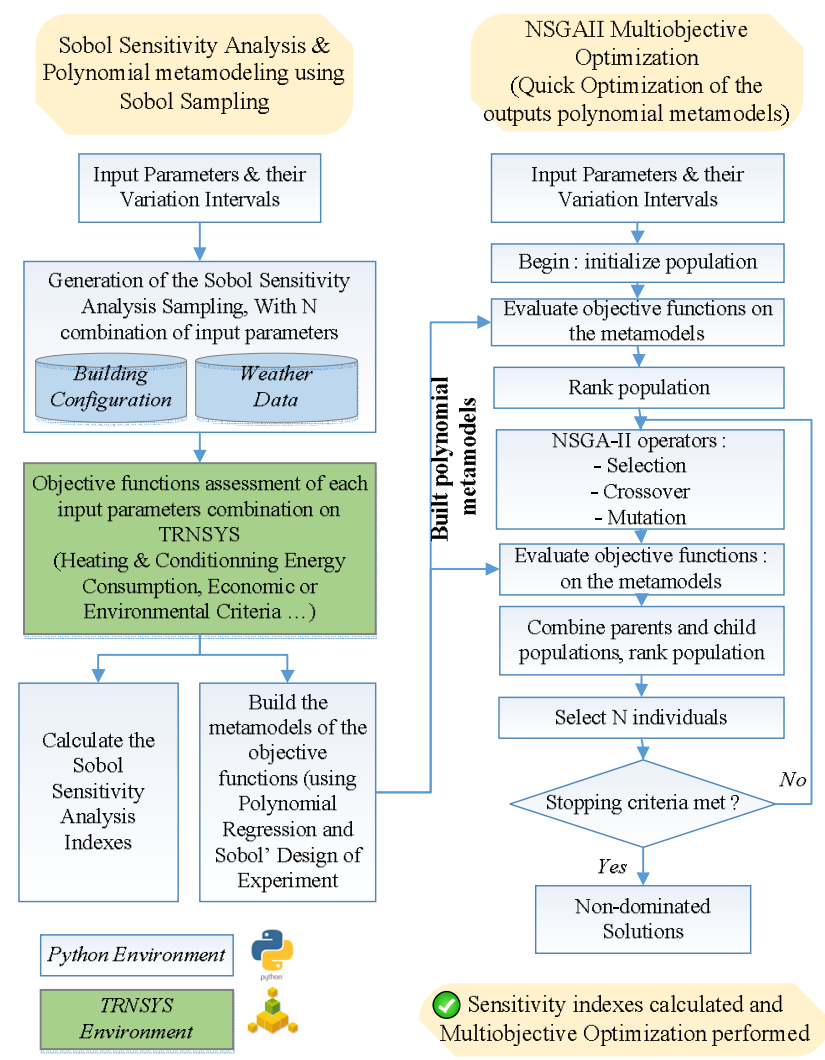

Fig. 1. Overall methodology.

Sensitivity analysis is an important step in the modeling process. It makes possible to rank the influence of the input parameters of a model on its outputs. Thus, it highlights the inputs with a large impact on the studied output, and in the same time the parameters with a negligible effect. The Sobol method is a relevant global sensitivity analysis method as it generates several sensitivity indices (by decomposing the variance of the output of the model). The first-order index allows assessing the impact of the variation of each parameter on the output, without studying its interaction with the other parameters. The total order index considers all the effects involving each parameter (first, second, and all other higher order effects due to parameter interactions). Therefore, in order to take advantage from the computational time for generating these sensitivity indices (calculation of each combination on TRNSYS), we propose to combine it to a metamodeling method using Artificial Neural Networks (ANNs). In fact, we consider the sampling of Sobol as a Design of Experiments (DoE), allowing us to train and build metamodels of the "Black-Box" functions' outputs of TRNSYS using polynomial regression methods. The sampling of Sobol trains the machine learning polynomial model of the output objective functions. Consequently, using Sobol sensitivity analysis, allows generating the sensitivity indices and instantaneously performing polynomial modeling of all the studied functions. This "instantaneous" prediction of the objective functions values is relevant to run efficient and quick multiobjective optimization.

\section{CASE STUDY}

SAMOT and TRNSYS were used to optimize the overall performance of a building in the city of Settat in Morocco, considering the effects of climate change, using the sequence shown in Figure 2.

\section{\begin{tabular}{|c|} 
Weather data, degree-days analysis using the B1 IPCC scenarios \\
Building model, input parameters \& objective functions presentation \\
Sensitivity Analysis: required number of iterations and results \\
Multiobjective Optimization using the polynomial metamodels and NSGA-II
\end{tabular}}

Fig. 2. Workflow sequence.

\section{A. Weather Data}

The studied location is the city of Settat-Nouaceur: $33.4^{\circ} \mathrm{N} /$ $-7.6^{\circ} \mathrm{E} / 206 \mathrm{~m}$. Settat has a warm climate with a dry summer. Year-round temperatures range from 2 (in January) to $40^{\circ} \mathrm{C}$ (in July), with an annual average of $17.9^{\circ} \mathrm{C}$. Solar horizontal irradiation can reach up to $1030 \mathrm{~W} / \mathrm{m}^{2}$.

\section{B. Climate Change Scenarios}

Meteonorm software allows the study of global warming according to different scenarios, defined by the IPCC (Intergovernmental Panel on Climate Change) [14]. We use these models to anticipate what would happen in the future under several conditions. Under the UN Paris Agreement, the countries are committed to limit global warming below $2{ }^{\circ} \mathrm{C}$ [15]. In our study, we will consider the B1 scenario (optimistic scenario, with $2^{\circ} \mathrm{C}$ warming by 2100). Figure 3 shows the evolution of the degree-days (DDs) in Settat, following this scenario.

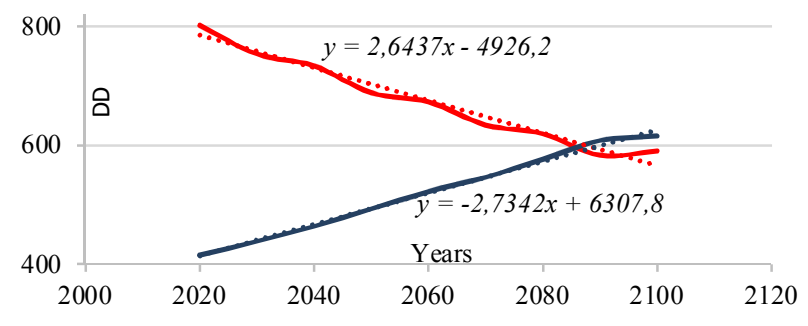

Fig. 3. Heating (in red) and cooling (in blue) DDs. 
Heating DDs decrease by $4.5 \%$ every decade, while cooling DDs increase at an average rate of $5.5 \%$. Both DD types equalize around 2085. Consequently, the current dominance of heating DDs will start reversing 2080 at the latest. The increasing dominance of the cooling DDs will jeopardize the current building design which is based on heating requirements. Furthermore, based on the B1 scenario, the current mean temperature in Settat $\left(17.9^{\circ} \mathrm{C}\right)$ will increase to $18.8^{\circ} \mathrm{C}$ by 2050 and to $19.6^{\circ} \mathrm{C}$ by 2100 . It is essential to take global warming into account to build comfortable buildings throughout their whole lifecycle.

\section{Building Model}

The model building designated for the study is a southfaced symmetrical $5 \mathrm{~m} \times 5 \mathrm{~m} \times 3 \mathrm{~m}$ square house. Each facade has a $3 \mathrm{~m}^{2}$ window. ADEREE [16] carried out the Moroccan thermal regulation based on the properties of the walls seen in Table I (excluding the additional layers of insulation for the roof and the low floor, and with an air slide for the external walls instead of insulation). The floor is in contact with the ground. Authors in [17] modeled the vertical distribution of the soil temperature and in [18] demonstrated that the latter depends on the time and the depth of the soil below the surface. TRNSYS type 77 implements these equations. The initial building model (without insulation) requires high heating and cooling needs $\left(185 \mathrm{kWh} / \mathrm{m}^{2} /\right.$ year $)$. In the following, we will present the input parameters and the objective functions of our model to improve its overall performance. For our study, we recommend the parameters exhibited in Table II.

TABLE I. WALL PROPERTIES

\begin{tabular}{|c|c|c|}
\hline & Materials & Width \\
\hline \multirow{3}{*}{ External walls } & Brick & $10 \mathrm{~cm}$ \\
\cline { 2 - 3 } & Insulation layer (glass wool) & Variable \\
\cline { 2 - 3 } & Brick & $10 \mathrm{~cm}$ \\
\hline \multirow{2}{*}{ Roof } & Filler slab & $16 \mathrm{~cm}$ \\
\cline { 2 - 3 } & Insulation layer (rock wool) & Variable \\
\hline \multirow{2}{*}{ Floor } & Insulation layer (rock wool) & Variable \\
\cline { 2 - 3 } & Reinforced concrete slab & $20 \mathrm{~cm}$ \\
\hline
\end{tabular}

TABLE II. INPUT PARAMETERS

\begin{tabular}{|c|c|c|c|c|c|}
\hline & Parameter & $\begin{array}{c}\text { Symb } \\
\text { ol }\end{array}$ & Unit & Low bond & High bond \\
\hline \multirow{3}{*}{ 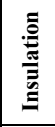 } & $\begin{array}{l}\text { External wall } \\
\text { insulation }\end{array}$ & $\mathrm{X}_{1}$ & $\mathrm{~m}$ & 0.001 & 0.1 \\
\hline & Roof insulation & $\mathrm{X}_{2}$ & $\mathrm{~m}$ & 0.001 & 0.1 \\
\hline & Floor insulation & $\mathrm{X}_{3}$ & $\mathrm{~m}$ & 0.001 & 0.1 \\
\hline \multirow{3}{*}{ 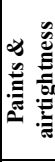 } & $\begin{array}{l}\text { External walls } \\
\text { painting color }\end{array}$ & $\mathrm{X}_{4}$ & - & 0.1 & 0.9 \\
\hline & $\begin{array}{l}\text { Roof painting } \\
\text { color }\end{array}$ & $\mathrm{X}_{5}$ & - & 0.1 & 0.9 \\
\hline & Air leakage & $\mathrm{X}_{6}$ & - & 0.3 & 1.15 \\
\hline \multirow{3}{*}{ 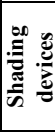 } & $\begin{array}{l}\text { South facing } \\
\text { window }\end{array}$ & $\mathrm{X}_{7}$ & - & 0 & 1 \\
\hline & East & $\mathrm{X}_{8}$ & - & 0 & 1 \\
\hline & West & $\mathrm{X}_{9}$ & - & 0 & 1 \\
\hline \multirow{4}{*}{ 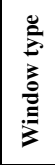 } & South & $\mathrm{X}_{10}$ & - & \multicolumn{2}{|c|}{ 0: Single, 1:Double, 2:Triple glazing } \\
\hline & North & $\mathrm{X}_{11}$ & - & \multicolumn{2}{|c|}{ 3:Low-emissivity double glazing } \\
\hline & East & $\mathrm{X}_{12}$ & - & \multicolumn{2}{|c|}{$\begin{array}{c}\text { 4:Low-emissivity double glazing } \\
\text { argon }\end{array}$} \\
\hline & West & $\mathrm{X}_{13}$ & - & \multicolumn{2}{|c|}{ 5: Solar-controlled triple glazing } \\
\hline
\end{tabular}

All the input parameters are continuous except for the window types (discrete). The use of shading devices (in \%) is applicable from mid-May to mid-October. Air infiltration varies between 0.3 (good airtightness) and $1.15 \mathrm{Vol} / \mathrm{h}$ (poor airtightness). We define the absorption coefficients according to the colors of the paints (e.g. 0.57 for dark red, 0.94 for black). To study the overall performance of our building (energetic, economic, and environmental), the selected functions are:

$$
\left\{\begin{array}{c}
f_{1}(X)=\text { Total Energy }(\text { Present }), \mathrm{kWh} / \mathrm{m}^{2} / \text { year } \\
f_{2}(X)=\text { Total Energy }(2050), \mathrm{kWh} / \mathrm{m}^{2} / \text { year } \\
f_{3}(X)=\text { Total Energy }(2100), \mathrm{kWh} / \mathrm{m}^{2} / \text { year } \\
f_{4}(X)=\text { Additional Cost, Moroccan Dirham }(M A D) \\
f_{5}(X)=\text { Additional Grey Energy, } \mathrm{kWh}
\end{array}\right.
$$

where $X$ is the input parameters vector. Total Energy is the sum of the heating and cooling requirements, with set temperatures equal to $20^{\circ} \mathrm{C}$ (heating) and $26^{\circ}$ (cooling). TRNSYS provides the values of this output. We will study the latter using the current weather data ( $f_{1}$ function), by $2050\left(f_{2}\right)$, and by 2100 $\left(f_{3}\right)$ using the IPCC B1 scenario of climate change. Additional Cost corresponds to the sum of the costs associated with the various additional implemented components. This indicator allows assessing the needed extra capital. $f_{4}$ function calculates the additional cost induced by the variation of the input parameters (thermal insulation and glazing types). Additional Grey Energy: To produce efficient buildings with a rational use of energy, it is essential to identify the environmental impacts of the different design solutions. During the construction or renovation of a building and during its entire life cycle, several environmental consequences must be predicted and optimized for several decades after its design. Non-renewable grey energy is required to initially produce a building and maintain it throughout its lifecycle. KBOB [19], a Swiss database contains life cycle assessment data for building materials, technical building installations, energy supply, transport and disposal processes, etc. As part of this work, we will use it to evaluate the grey energy of the various solutions studied for our model building.

\section{Sensitivity ANALYSIS}

\section{A. Process}

The proposed prossess is shown in Figure 4.

$\begin{gathered}\text { Generate a Sobol sampling Matrix with } \mathrm{N} x(\mathrm{p}+2) \text { combinations, where } \mathrm{N} \text { is } \\ \text { specified by the user and } \mathrm{p} \text { is the number of input parameters }\end{gathered}$
Assess the values of the output functions on TRNSYS
$\begin{gathered}\text { Calculate the variance-based sensitivity indexes: First order indexes } \\ \text { (Without taking into accound the impact of interactions between input } \\ \text { parameters) and total order indexes }\end{gathered}$

Fig. 4. Sensitivity analysis indices calculation sequence.

\section{B. Recommended Number of Simulations}

One of the main difficulties in carrying out sensitivity analysis is choosing the adequate number of model simulations (number of combinations of Sobol's sampling matrix), prior to the calculation of sensitivity indices. Authors in [20] carried 
out a classification of sensitivity analysis methods according to the number of model evaluations. They reported that Sobol's method requires at least 1000 . To determine the recommended value of $\mathrm{N}$, we assess the error coefficient (ST_Conf) on the calculation of the total-order indices of Sobol, for $\mathrm{N}$ from 10 to 100 (pitch of 10) and from 100 to 2000 (pitch of 100). We compare the error coefficients for the $f_{1}$ function. Figure 5 shows the results.

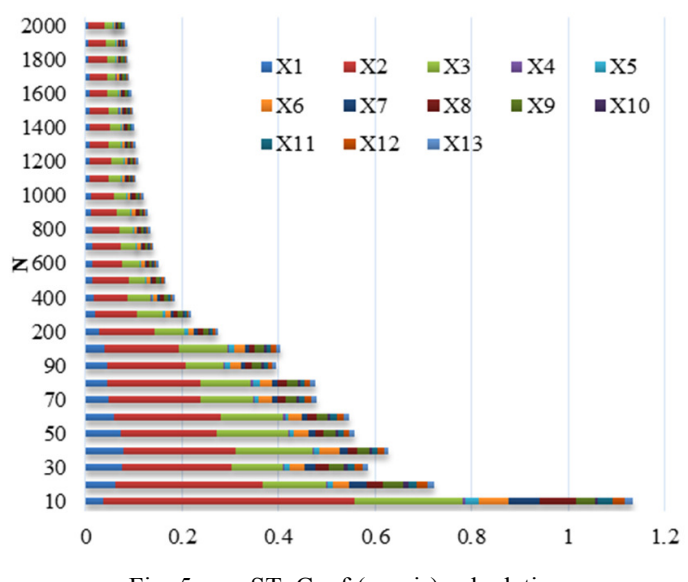

Fig. 5. ST Conf (x-axis) calculation.

We notice that the ST Conf indices stabilize around $\mathrm{N}=1000$, and stat getting acceptable values from $\mathrm{N}=500$. Consequently, we recommend choosing a value of $\mathrm{N}>500$, which corresponds in our case study to $15 \times 500=7500$ simulations.

\section{Sensitivity Analysis Indices}

We calculate Sobol's [21] total-order sensitivity indices for the black-box functions $f_{1}, f_{2}$ and $f_{3}$. When the total-order is positive, increasing the input parameter value increases the output function, and vice-versa.

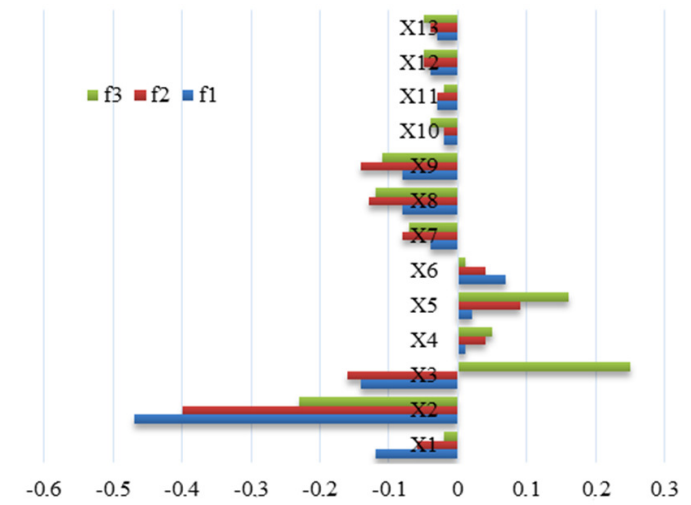

Fig. 6. Total order sensitivity indexes for the functions $f_{1}, f_{2}$ and $f_{3}$.

For the model building, it is deduced from the analysis that:

- The most influential parameter for the three functions is the roof insulation $\left(\mathrm{X}_{2}\right)$.

- The use of shading devices $\left(X_{7}\right.$ to $\left.X_{9}\right)$ has a greater impact than the variation in the glazing type $\left(\mathrm{X}_{10}\right.$ to $\left.\mathrm{X}_{13}\right)$.
Furthermore, the use of shading devices acquires more importance over time, given the unceasing increase of cooling degrees days as detailed before.

- Insulating the floor increases the energy needs in 2100 , as it does not allow benefiting from the coolness of the ground during the summer to lower indoor temperatures.

- Dark color use for the roof and the exterior walls increases the energy requirements as time passes. The use of light colors is therefore recommended.

\section{MultiobJective OPTIMIZATION}

In this section the optimization problem in (2) is studied:

$$
\left\{\begin{array}{c}
\text { Minimize }: f_{1}(X), f_{2}(X), f_{3}(X), f_{4}(X), f_{5}(X) \\
\text { Under constraints : } \\
f_{1}(X), f_{2}(X), f_{3}(X) \leq 40 \mathrm{kWh} / \mathrm{m}^{2} / \text { year }
\end{array}\right.
$$

We can perform polynomial regression using any polynomial order (although above a 5-order model the calculation time explodes). Nevertheless, authors in [22] advice against the use of high-order polynomial regressions and recommend the use of linear and quadratic models. In the following, we will compare the accuracy of four polynomial models (see Table III) based on Mean Absolute Error (MAE) and $R^{2}$ :

$$
\begin{gathered}
M A E=\frac{1}{N} \sum_{i=1}^{N}\left|y_{i}-\hat{y}_{i}\right| \\
r-\operatorname{value}\left(\text { or } R^{2}\right)=\frac{\sum_{i=1}^{N}\left(\hat{y}_{i}-\bar{y}\right)^{2}}{\sum_{i=1}^{N}\left(y_{i}-\bar{y}\right)^{2}}
\end{gathered}
$$

where $N$ is the number of input combinations, $y_{i}$ is the value of the output function to model (calculated using TRNSYS), $\hat{y}_{i}$ is the predicted value of the output function and

$$
\bar{y}=\frac{1}{N} \sum_{i=1}^{N} y_{i}
$$

is the mean value of the function. We randomly generate 100

\begin{tabular}{|c|c|c|c|c|}
\hline Function & First Order & $\begin{array}{c}\text { Second order, } \\
\text { interactions } \\
\text { only }\end{array}$ & $\begin{array}{c}\text { Complete } \\
\text { second order }\end{array}$ & $\begin{array}{c}\text { Third order, } \\
\text { interactions } \\
\text { only }\end{array}$ \\
\hline Present: $f_{l}$ & $\begin{array}{c}R^{2}=0.81 \\
M A E=8.6\end{array}$ & $\begin{array}{c}R^{2}=0.8 \\
M A E=8.4\end{array}$ & $\begin{array}{c}R^{2}=0.87 \\
M A E=8.7\end{array}$ & $\begin{array}{c}R^{2}=0.74 \\
M A E=10.1\end{array}$ \\
\hline 2050: $f_{2}$ & $\begin{array}{c}R^{2}=0.84 \\
M A E=11.6\end{array}$ & $\begin{array}{c}R^{2}=0.84 \\
M A E=11.7\end{array}$ & $\begin{array}{c}R^{2}=0.91 \\
M A E=10.1\end{array}$ & $\begin{array}{c}R^{2}=0.79 \\
M A E=11.3\end{array}$ \\
\hline 2100: $f_{3}$ & $\begin{array}{c}R^{2}=0.88 \\
M A E=5.3\end{array}$ & $\begin{array}{c}R^{2}=0.91 \\
M A E=4.6\end{array}$ & $\begin{array}{c}R^{2}=0.94 \\
M A E=3.7\end{array}$ & $\begin{array}{c}R^{2}=0.88 \\
M A E=5.6\end{array}$ \\
\hline
\end{tabular}
new combinations of input parameters to assess the accuracy of the metamodels.

TABLE III. MAE AND $R^{2}$ OF THE FOUR MODELS

For our case study, we notice that the best regression model for the three functions (total energy at 2020, by 2050, and by $2100)$ is the complete 2 -order polynomial model. $R^{2}$ coefficients are generally above 0.9 . We notice also that the quality of the regression deteriorates for the third-order model, the built model gets in fact too "specialized" in the input sampling (learning model), and the prediction of the results of new random samplings is then less accurate (overfitting issue). Therefore, we recommend the use of the complete 2 nd-order model, which is a good compromise between precision and 
computation time. The 2D projections of the Pareto front of the optimization problem are shown in Figure 7. The Pareto front is widely used in multiobjective optimization as it allows choosing the best results through the notion of dominance [23].
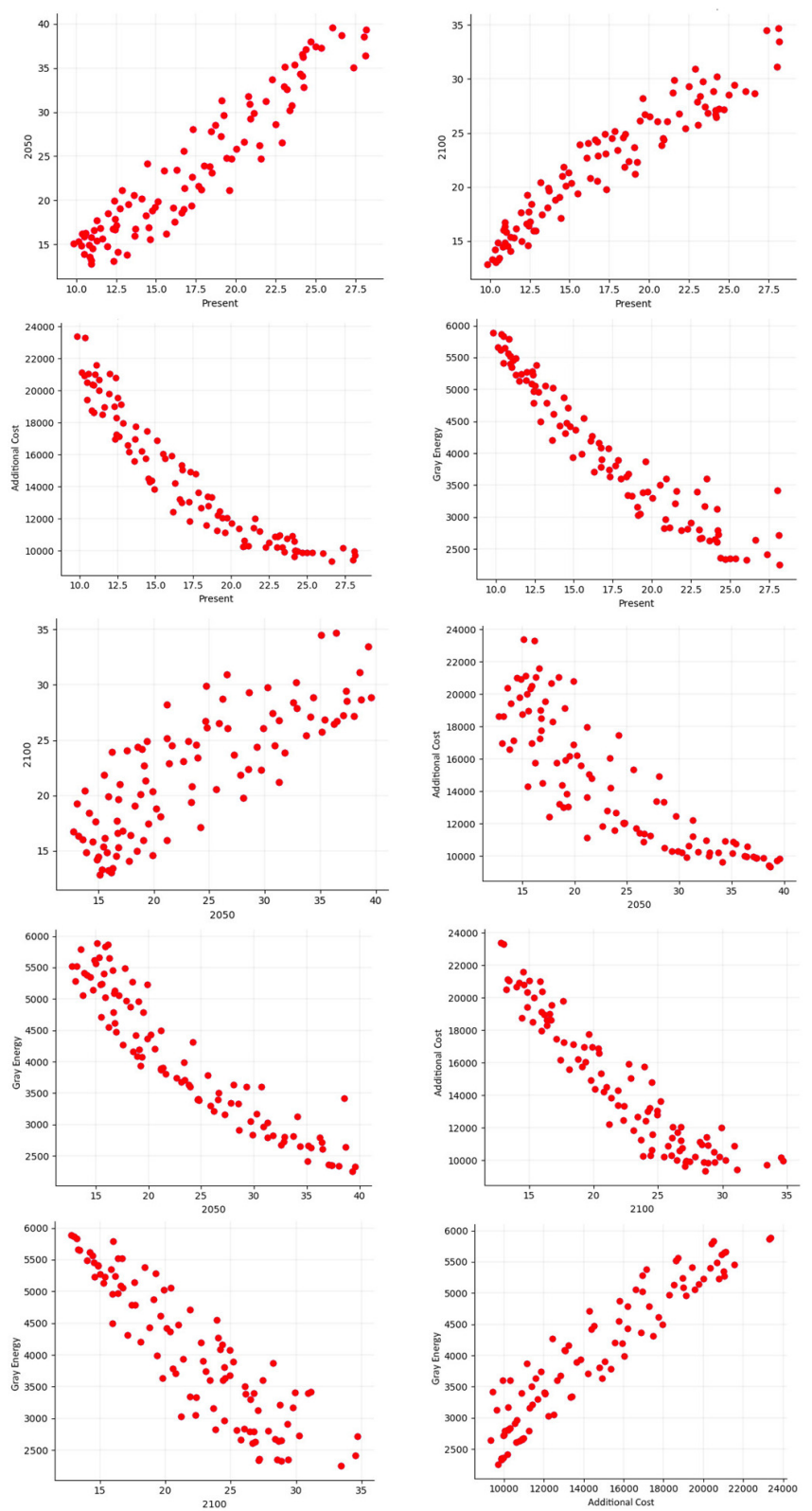

Fig. 7. Multiobjective optimization's non-dominant results-2D projections.

The following conclusions can be drawn from the optimization:

- The need to insulate the roof and the exterior walls to keep a high-performance building by 2100 .

- The floor requires a moderate insulation. In fact, the excess of insulation implies increasing the energy requirements by 2100 as deduced before from the Sobol indices.
- The external wall paint must be clear (e.g. white to orange) by 2100 . The roof paint must be clear for all time frames (present, 2050, and 2100).

- The infiltration rates must be very low (excellent airtightness).

- The necessity of using shading devices for the three facades.

- The North and East facade glazing must be efficient on the current horizon and the west one should perform well by 2050 .

- For the cheapest optimal variant, the insulation of the floor is not proposed, the paints are white and all facades have triple glazing.

- For the most environment-friendly variant, the highest quality of glazing is in the northern facade. The other facades have single or double-glazing.

In Table IV, we display a comparison of the best-predicted solutions (1) for the 3 functions and their TRNSYS simulationbased results (2). The predicted values are very close to the simulation-based ones.

TABLE IV. OPTIMAL SOLUTIONS AND RESULT COMPARISON

\begin{tabular}{|c|c|c|c|c|c|c|c|}
\hline \multicolumn{2}{|c|}{$\boldsymbol{f}_{\mathbf{1}}:$ Present } & \multicolumn{2}{|c|}{$\boldsymbol{f}_{\mathbf{2}}: \mathbf{2 0 5 0}$} & \multicolumn{2}{|c|}{$\boldsymbol{f}_{\mathbf{3}}: \mathbf{2 1 0 0}$} & \multirow{2}{*}{$\boldsymbol{f}_{\mathbf{4}}$} & \multirow{2}{*}{$\boldsymbol{f}_{\mathbf{5}}$} \\
\hline$(1)$ & $(2)$ & $(1)$ & $(2)$ & $(1)$ & $(2)$ & & \\
\hline 9.9 & 13.3 & 13.5 & 11.3 & 13.8 & 15.5 & 23380 & 6343 \\
\hline 9.7 & 14.2 & 12.4 & 11.7 & 14.0 & 16.0 & 22952 & 6099 \\
\hline 10.3 & 16.7 & 16.6 & 10.7 & 12.3 & 13.1 & 24837 & 6511 \\
\hline
\end{tabular}

(1) : Regression, (2) TRNSYS based

\section{DISCUSSION}

We demonstrated through the case study that our methodology gives very efficient and satisfying results. The use of polynomial regression allows to model the "black-box" objective functions of TRNSYS with good accuracy, and to obtain optimization results within only a few minutes. Thanks to this method, we can significantly reduce the calculation time compared to running direct optimizations on TRNSYS. Furthermore, our methodology helps understanding the building model, through ranking the input parameters impact and their interactions, highlighted by the sensitivity analysis indices. Sensitivity analysis and mono / multiobjective optimization are used independently, although these two methodologies are complimentary. Our work will contribute to further combining these methods together, in order to provide the field decision-making stakeholders with relevant indicators at the early stages of the design of the buildings.

\section{CONCLUSION}

This work takes part in the current process of improving energy efficiency performance in the building sector. Its main purpose is to develop efficient methodologies to study and to optimize the overall performance of buildings. In accordance with this objective, we developed the Sensitivity Analysis and Multiobjective Optimization Tool (SAMOT) to combine the strengths of sensitivity analysis and multiobjective 
optimization, and to provide an efficient decision-aiding tool to building designers and researchers. Sensitivity analysis allows understanding the impact of varying the value of input parameters (envelope, systems, etc.). Sensitivity indices rank the impact of the latter on the outputs. We recommend a minimal Sobol matrix sampling size of $500 \times(N+2)$, with $N$ being the number of input parameters. In our case, the variation of the roof insulation influences largely the present and the forecasted 2050 and 2100 energy requirements.

To optimize the overall performance of our inefficient building model $\left(185 \mathrm{kWh} / \mathrm{m}^{2} /\right.$ year of heating and cooling needs), a constrained (thermal regulation thresholds) 5-criteria problem is studied on TRNSYS and SAMOT. We recommended the use of a $2^{\text {nd }}$-order polynomial regression to avoid overfitting / under fitting issues. In our case, the correlation coefficients were generally higher than $90 \%$ for a random 100 new combinations set. The results are satisfactory and quasi simultaneous. This new method allows calculating Sobol sensitivity analysis and then performing quick parallel optimization. Our case study underlines the necessity of taking into account climate change in building design. We demonstrated also the worthiness of the proposed SAMOT tool for building performance optimization.

\section{REFERENCES}

[1] 2018 Global Status Report - Towards a zero-emission, efficient and resilient buildings and construction sector. International Energy Agency, 2018.

[2] A. L. Rizor and A. Corn, "Design Criteria and Solutions to Common Issues in Building Envelope Design," in Building Science and the Physics of Building Enclosure Performance, D. J. Lemieux and J. Keegan, Eds. West Conshohocken, PA, USA: ASTM International, 2020, pp. 195-210.

[3] J. Vivian, U. Chiodarelli, G. Emmi, and A. Zarrella, "A sensitivity analysis on the heating and cooling energy flexibility of residential buildings," Sustainable Cities and Society, vol. 52, Jan. 2020, Art. no. 101815, https://doi.org/10.1016/j.scs.2019.101815.

[4] M. Rohani, G. Shafabakhsh, A. Haddad, and E. Asnaashari, "Sensitivity Analysis of Workspace Conflicts According to Changing Geometric Conditions," Engineering, Technology \& Applied Science Research, vol. 7, no. 1, pp. 1429-1435, Feb. 2017, https://doi.org/10.48084/etasr.1012.

[5] Z. Yong, Y. Li-juan, Z. Qian, and S. Xiao-yan, "Multi-objective optimization of building energy performance using a particle swarm optimizer with less control parameters," Journal of Building Engineering, vol. 32, Nov. 2020, Art. no. 101505, https://doi.org/ 10.1016/j.jobe. 2020.101505 .

[6] H. R. Mafakheri, A. H. Hejazi, and M. Dashti, "Design of the Administrative Building of Kuhsar City under a Sustainable Architecture Concept Approach," Engineering, Technology \& Applied Science Research, vol. 6, no. 4, pp. 1080-1083, Aug. 2016, https://doi.org/ 10.48084/etasr.723.

[7] D. Mazzeo, N. Matera, C. Cornaro, G. Oliveti, P. Romagnoni, and L. De Santoli, "EnergyPlus, IDA ICE and TRNSYS predictive simulation accuracy for building thermal behaviour evaluation by using an experimental campaign in solar test boxes with and without a PCM module," Energy and Buildings, vol. 212, Apr. 2020, Art. no. 109812, https://doi.org/10.1016/j.enbuild.2020.109812.

[8] M. Palonen, M. Hamdy, and A. Hasan, "MOBO a new software for multi-objective building performance optimization," in Proceedings of the 13th Internationcal Conference of the IBPSA, 2013.

[9] A. Serbouti, M. Rattal, A. Boulal, M. Harmouchi, and A. Mouhsen, "Application of sensitivity analysis and genopt to optimize the energy performance of a building in Morocco," International Journal of
Engineering \& Technology, vol. 7, no. 4, pp. 2068-2074, Sep. 2018, https://doi.org/10.14419/ijet.v7i4.13280.

[10] A. Serbouti, M. Rattal, A. Boulal, E. M. Oualim, and A. Mouhsen, "Multi-Objective Optimization of a Family House Performance and Forecast of its Energy Needs by 2100," International Journal of Engineering \& Technology, vol. 7, no. 4.32, pp. 7-10, Dec. 2018, https://doi.org/10.14419/ijet.v7i4.32.23235.

[11] J. Herman and W. Usher, "SALib: An open-source Python library for Sensitivity Analysis," Journal of Open Source Software, vol. 2, no. 9 , Jan. 2017, Art .no. 97, https://doi.org/10.21105/joss.00097.

[12] D. Brockhoff and T. Tušar, "Benchmarking algorithms from the platypus framework on the biobjective bbob-biobj testbed," in Proceedings of the Genetic and Evolutionary Computation Conference Companion, New York, NY, USA, Jul. 2019, pp. 1905-1911, https://doi.org/ 10.1145/3319619.3326896.

[13] F. Pedregosa et al., "Scikit-learn: Machine Learning in Python," Journal of Machine Learning Research, vol. 12, pp. 2825-2830, Nov. 2011.

[14] Core Writing Team, L. Mayer, and R. K. Pachauri, Eds., Climate change 2014: synthesis report. Geneva, Switzerland: IPCC, 2015.

[15] M. C. Hänsel et al., "Climate economics support for the UN climate targets," Nature Climate Change, vol. 10, no. 8, pp. 781-789, Aug. 2020, https://doi.org/10.1038/s41558-020-0833-x.

[16] Règlement thermique de construction au Maroc (RTCM). ADEREE, 2014.

[17] T. Kusuda, O. Piet, and J. W. Bean, "Annual variation of temperature field and heat transfer under heated ground surfaces (slab-on-grade floor heat loss calculation)," Building science series, vol. 1983, no. 156.

[18] G. Florides and S. Kalogirou, "Ground heat exchangers - A review of systems, models and applications," Renewable Energy, vol. 32, no. 15 , pp. 2461-2478, Dec. 2007, https://doi.org/10.1016/j.renene.2006.12.014.

[19] KBOB : Données des écobilans dans la construction 2009/1:2014. IPB, KBOB, 2014.

[20] B. Iooss, "Revue sur l'analyse de sensibilité globale de modèles numériques," Journal de la Societe Française de Statistique, vol. 152, no. 1, pp. 1-23, 2011.

[21] I. M. Sobol', "Global sensitivity indices for nonlinear mathematical models and their Monte Carlo estimates," Mathematics and Computers in Simulation, vol. 55, no. 1, pp. 271-280, Feb. 2001, https://doi.org/ 10.1016/S0378-4754(00)00270-6.

[22] A. Gelman and G. Imbens, "Why High-Order Polynomials Should Not Be Used in Regression Discontinuity Designs," Journal of Business \& Economic Statistics, vol. 37, no. 3, pp. 447-456, Jul. 2019, https://doi.org/10.1080/07350015.2017.1366909.

[23] F. Ascione et al., "A real industrial building: Modeling, calibration and Pareto optimization of energy retrofit," Journal of Building Engineering, vol. 29, May 2020, Art. no. 101186, https://doi.org/10.1016/j.jobe.2020. 101186 . 